\title{
KNOWLEDGE OF YOUTH ON SUSTAINABLE DEVELOPMENT GOALS
} (SDGS)

\section{Dr. D. Prince Annadurai}

\author{
Assistant Professor, Department Of Social Work, Madras Christian College, \\ Tambaram. Chennai- 600059
}

ABSTRACT

The Sustainable Development Goals (SDGs) is the successor to the Millennium Development Goals (MDGs) and is widely known as Agenda 2030, and it should have been attained globally. This study was conducted with an aim to access the knowledge of youth on Sustainable Development Goals (SDGs) to know the awareness on SDGs, to find out the contributions towards SDGs and to find out whether any difference exists between gender and age groups with regard to their awareness on SDGs. The study was conducted in three districts of Tamil Nadu and was descriptive in nature. An interview schedule was used as tool of data collection. The total sample size was 628 . Four Hundred young boys and girls (School students) in the age group of 11-18 years were selected from the schools by using Simple Random Lottery method. Then, 258 young boys and girls in the age group of 18-25 years were selected from out of schools by using Purposive sampling. The main findings of the study were, the awareness about SDGs was very low among the respondents. There was no difference between male and female respondents in their ignorance of SDGs. The same is for different age groups. None of the respondents contribute to SDGs mainly due to lack of awareness. It was suggested that the school teachers and PHC staff have crucial roles to play in creating awareness as well as providing SDGs and the services to young people both inside and outside schools

\section{KEYWORDS : Sdgs, Mdgs, Youth}

\section{INTRODUCTION}

The Sustainable Development Goals (SDGs) is a globally accepted developmental agenda, and it is expected that everyone everywhere in the world would be aware, knowledgeable and be willing to contribute to its attainment. This study aims to assess the level of awareness, knowledge towards the SDGs among members of adolescents and young people in selected districts of Tamil Nadu.

Today, there are 1.8 billion people between the ages of 10 24 - they are the largest generation of youth in history. Close to 90 per cent of them live in developing countries, where they make up a large proportion of the population. Their numbers are expected to grow-between 2015 and 2030 alone, about 1.9 billion young people are projected to turn 15 years old (Connolly 2008). Connected to each other like never before, young people want to and already contribute to the resilience of their communities, proposing innovative solutions, driving social progress and inspiring political change. They are also agents of change, mobilizing to advance the Sustainable Development Goals to improve the lives of people and the health of the planet (UN 2017)

Provided with the necessary skills and opportunities needed to reach their potential, young people can be a driving force for supporting development and contributing to peace and security. Youth-led organizations need to be encouraged and empowered to participate in translating the 2030 Agenda into local, national and regional policy (Ogbodo 2015). They play a significant role in the implementation, monitoring and review of the Agenda as well as in holding governments accountable (Nashash 2013). With political commitment and adequate resources, young people have the potential to make the most effective transformation of the world into a better place for all (Mc Donnell 2011).

\section{OBJECTIVE OF THE STUDY}

To access the knowledge of youth on Sustainable Develo pment Goals (SDGs)

\section{SPECIFIC OBJECTIVES}

1. To know the awareness on SDGs

2. To find out the contributions towards SDGs

3. To find out whether any difference exists between gender and age groups with regard to their awareness on SDGS.

\section{FIELD OF STUDY}

The study was carried out in three districts of Tamil Nadu, i,e . Kanchipuram, Thiruvallur and Vellore Districts of Tamil Nadu in the year 2017.

\section{RESEARCH DESIGN:}

The study was done using Descriptive design and it described the knowledge and practice on sexual and reproductive health resources available in the community,

\section{SAMPLING SIZE AND SAMPLING TECHNIQUE}

Simple random sampling technique using lottery method was used in the schools to collect the respondents. Since out of school youth were floating in nature, purposive sampling technique was used to collect the respondents as per their availability and interest.

400 young boys and girls (School students) in the age group of 11-18 years were selected from the schools by using Simple Random Lottery method. Then, 258 young boys and girls in the age group of 18-25 years were selected from out of schools (62 each from Vellore 1,Vellore 2, Thiruvallur and Kanchipuram) by using Purposive sampling. So the total sample in this study was 658.

\section{TOOL OF DATA COLLECTION}

A comprehensive interview schedule prepared by the researcher was used as tool of data collection to assess the youth in school and out of school.

\section{ETHICAL CONSIDERATIONS IN THIS STUDY}

1. Informed consent was taken from the respondents. They had the option to discontinue the interview at any point of time they felt not comfortable. No respondents were forced to participate in this study.

2. All the interviews with the school youths were done in a separate room (most often and wherever possible) to insure confidentiality.

\section{MAIN FINDINGS}

\section{KNOWLEDGE OF YOUTH ON SDGS}

A vast majority of $93 \%$ the respondents were not aware of SDGs and number of SDGs. A majority of the respondents were neither aware nor able to give correct answer regarding the names of SDGs. A majority of the respondents were not 
aware of the formation of SDGs. Since a vast majority of the respondents were not aware of SDGs, they were not sure of contributing to SDGs A majority of the respondents were neither aware of SDGs nor their activity in community contributing to the goals of SDGs. A majority of the respondents were neither aware nor able to do something in the community contributing to SDGs. $22 \%$ of the respondents were undecided about it.

\section{GENDER AND KNOWLEDGE OF YOUTH ON SDGS}

Both male and female respondents were not aware of the number of SDGs. Both male and female respondents were not able to name the SDGs. A majority (78\%) of both male and female respondents were not aware of the formation of SDGs. A majority of both male and female respondents were not willingness to contribute to SDGs. A majority of both male and female respondents were not involving in any activity in community contributing towards SDGs. A majority of both male and female respondents were not planning to do something in the community contributing towards SDGs

\section{AGE AND KNOWLEDGE OF YOUTH ON SDGS}

Respondents' awareness about SDGs is very poor and negligible (Less than $4 \%$ in the age group of $10-20$ years and 21-30 years). Respondents' awareness about the number of SDGs is very poor irrespective of the age. Among all the age groups, the respondents were not able to name the SDGs. Among all the age groups, the respondents' awareness on the formation of SDGs is very poor. Among all the age groups, the respondents' willingness to contribute to SDGs is very poor. Among all the age groups, the respondents' activity in community contributing towards SDGs is very poor. Among all the age groups, the respondents' planning to do something in the community contributing towards SDGs' is very poor. However, $17 \%$ of the respondents said that they have not yet decided about it.

\section{SUGGESTIONS}

It is a challenge and opportunity for the PRIs to make aware of the respondents about SDGs and they should be educated to make use of Government schemes that is in line with SDGs in the communities. The village sanitation committees, Poverty Reduction Committees, adolescent groups created by the $\mathrm{PHCs}$, local fan clubs can be effectively used to impart knowledge on SDGs. Youth participation in PRIs will certainly bring a major change in the knowledge of the SDGs. Another practical suggestion is, school teachers can act as a catalyst in imparting this knowledge. SDGs can become part of the curriculum in the schools.

\section{DISCUSSION}

Globally and locally there has been a lot of focus on achieving SDGs. Part of being young involves making sense of personal experiences and asking questions about the world around them. Youth have the capacity to identify and challenge existing power structures and barriers to change, and to expose contradictions and biases. Young people also have the power to act and mobilise others. Youth activism is on the rise the world over, bolstered by broader connectivity and access to social media. In addition to bringing fresh perspectives, young people often have direct knowledge of and insights into issues that are not accessible to adults. Youth best understand the problems they face and can offer new ideas and alternative solutions. Young people can be partners in communicating the development agenda to their peers and communities at the local level, as well as across countries and regions. When young people are empowered with the knowledge of their rights and equipped with leadership skills, they can drive change in their communities and countries. fair. However, the level of knowledge was abysmally low, and this has serious negative implications for SDGs attainment. Pertinent individual and population-level methods of enlightening people about the SDGs must be put in place in educational settings; curricular changes are imperative. Youth-led organisations and networks, in particular, should be supported and strengthened, because they contribute to the development of civic leadership skills among young people, especially marginalised youth.

\section{REFERENCES}

1. Connolly E, Doyle J, Dwyer F. "Public opinion and development issues: A survey of the Irish university student opinions" Irish Studies in International Affairs. $2008 ; 19: 20$

2. European Union, Special Eurobarometer 441 Report. EU Development Cooperation and Aid. The European Year for Development-Citizens' views on Development, Cooperation and Aid. 2016. [16 June 2017]. Available at http://ec.europa.eu/europeaid/special-eurobarometer-44l-european-yeardevelopment-citizens-viewson-development-cooperation-and-aid_en

3. Fransman J, MacDonald AL, Mc Donnell I, Pons-Vignon N. OECD Development Centre. Working Paper No. 238. Public opinion polling and the millennium development goals. 2004. Oct

4. GlobeScan, author. Awareness of SDGs versus MDGs: How Engaged Are Global Citizens? OECD DevCom Annual Meeting. 2016. [16 June 2017]. Available athttps://www.oecd. org/dev/pgd/Sessio n4_Bouhana_Globe Scan OECDTalk MDGsvsSDGs 2016.pdf.

5. Inter-Ägency and Expert Group on SDG Indicators (IAEG-SDGs), author Final list of proposed Sustainable Development Goal indicators. 2016. Mar, [12/12/2016]. Available athttp://unstats.un.org/sdgs/i ndicators/Official\%20L ist\%20of\%20Proposed\%20SDG\%20Indicators.pdf.

6. Mc Donnell I. An International Perspective on Communication Strategies for the Millennium Development Goals. NCDO and OECD Development Centre2011

7. Nashash $\mathrm{H}$. Level of millennium development goals awareness among students at Princess Alia University College. European Scientific Journal. 2013;9(16):43-54

8. Ogbodo JN. Nigerian public awareness and knowledge of the Millennium Development Goals (MDGs) and their Level of implementation in Nigeria. European Scientific Journal. 2015;1 1(23):301-316.

9. United Nations, author. Sustainable Development Knowledge Platform. Future We Want - Outcome document. [25 March 2017]. Available athttps://sustainabledevelopment.un.org/futurewewant.html.

10. UNDP Nigeria, 2030, Agenda for Sustainable Development. [12/12/2016] Available at: http://www.ng.undp.org/content/nigeria/en/home/post2015/sdg-overview.html.

\section{CONCLUSION}

The awareness of and attitudes towards the SDGs was just 